\title{
Estratégias de gamificação: um sistema web para disseminar as informações de produção para os trabalhadores da construção civil
}

\author{
Gamification Strategies: a web system to disseminate production information to construction
}

workers

Estrategias de gamificación: un sistema web para difundir información de producción a los
trabajadores de la construcción

Recebido: 06/09/2021 | Revisado: 15/09/2021 | Aceito: 18/09/2021 | Publicado: 19/09/2021

\author{
Regina Maria Cunha Leite \\ ORCID: https://orcid.org/0000-0002-5388-3092 \\ Instituto Federal da Bahia, Brasil \\ E-mail: regina.leite@ifba.edu.br \\ Lynn Rosalina Gama Alves \\ ORCID: https://orcid.org/0000-0003-3688-3506 \\ Universidade Federal da Bahia, Brasil \\ E-mail: lynnalves@gmail.com
}

\begin{abstract}
Resumo
A indústria da construção civil tem procurado se modernizar para acompanhar as mudanças tecnológicas que vem ocorrendo no cotidiano das pessoas, porém a falta de transparência no processo de construção leva a dificuldade de entendimento pelos operários e a problemas de comunicação entre os níveis tático e operacional. Este artigo tem o objetivo de discutir e apresentar a solução desenvolvida para facilitar a comunicação entre trabalhadores e gestores no canteiro de obras a fim de melhorar o entendimento das metas de trabalhos. Trata-se de uma pesquisa exploratória com abordagem metodológica Design Science usando o método o Design Science Research. A pesquisa foi dividida em três fases, a saber: (1) Compreensão, (2) Desenvolvimento, (3) Avaliações. O presente artigo corresponde a fase de desenvolvimento da solução, envolvendo análise de requisitos dos gestores e trabalhadores da construção civil a fim de elaborar um sistema web com interface gamificada. A partir das informações produzidas e da revisão bibliográfica desenvolveu-se um sistema gamificado. O contexto da construção civil evidência que os trabalhadores possuem carência de reconhecimento e têm baixa escolaridade. A interação com esses sujeitos indicou que a inserção de estratégias gamificadas poderia contribuir para a melhoria da comunicação. Os resultados apontam que a solução proposta pode minimizar estes problemas.
\end{abstract}

Palavras-chave: Gamificação; Comunicação; Inovação; Produção; Construção civil.

\begin{abstract}
The construction industry has sought to modernize itself to keep up with the technological changes that have been taking place in people's daily lives, but the lack of transparency in the construction process leads to difficulties in understanding by workers and communication problems between the tactical and operational levels. This article aims to propose a solution to facilitate communication between workers and managers at the construction site to improve the understanding of work goals. This is exploratory research with a Design Science methodological approach using the Design Science Research method. The research is divided into three phases, namely: (1) Understanding, (2) Development and (3) Assessments. The article corresponds to the solution development phase. Involving analysis of requirements of managers and construction workers to develop a web system with a gamified interface. From the information produced and the literature review, a gamified system was developed. Most workers have a huge lack of recognition and have a low level of education, which justifies the inclusion of gamified strategies to improve communication. The results show that the proposed solution can minimize this problem.
\end{abstract}

Keywords: Gamification; Communication; Innovation; Production; Construction.

\section{Resumen}

La industria de la construcción ha buscado modernizarse para mantenerse al día con los cambios tecnológicos que se vienen produciendo en el día a día de las personas, pero la falta de transparencia en el proceso constructivo genera dificultades de entendimiento por parte de los trabajadores y problemas de comunicación entre los niveles táctico y operativo. Este artículo tiene como objetivo proponer una solución para facilitar la comunicación entre trabajadores y gerentes en el sítio de construcción con el fin de mejorar la comprensión de los objetivos del trabajo. Se trata de una 
investigación exploratoria con un enfoque metodológico de la ciencia del diseño utilizando el método de investigación de la ciencia del diseño. La investigación se divide en tres fases, a saber: (1) Comprensión, (2) Desarrollo y (3) Evaluaciones. El artículo corresponde a la fase de desarrollo de la solución. Implica el análisis de los requerimientos de los gerentes y trabajadores de la construcción para desarrollar un sistema web con una interfaz gamificada. A partir de la información producida y la revisión de la literatura, se desarrolló un sistema gamificado. La mayoría de los trabajadores tiene una enorme falta de reconocimiento y poca educación, lo que justifica la inclusión de estrategias ludificadas para mejorar la comunicación. Los resultados muestran que la solución propuesta puede minimizar este problema.

Palabras clave: Gamificación; Comunicación; Innovación; Producción; Construcción.

\section{Introdução}

A indústria da construção civil tem procurado se modernizar para acompanhar as mudanças tecnológicas que vem ocorrendo no cotidiano das pessoas como o uso de dispositivos móveis, redes sociais e inteligência artificial. Estas mudanças têm proporcionado uma verdadeira revolução na sociedade, possibilitando ações antes inimagináveis a fim de melhorar a qualidade de vida, o controle, a vigilância entre outros aspectos. Em busca de uma gestão mais eficiente, os gerentes abrem espaço para novas abordagens, a fim de promover melhorias para o cumprimento das metas de produção (Brady et al., 2018; Mariz et al., 2019, Bascoul et al., 2020)

Pesquisas têm apontado a importância de desenvolver métodos ou inovações tecnológicas que possam alavancar o desempenho da gestão da construção (Pérez et al., 2019; Alvarez et al., 2019; Pérez \& Costa, 2020; Sawhney et al., 2020). No contexto brasileiro iniciativas têm sido implementadas pelo governo com o objetivo de colocar a indústria nacional no caminho desta transformação digital, a exemplo Decreto $\mathrm{n}^{\circ}$ 9.983, de 22 de agosto de 2019 que tem como finalidade promover um ambiente adequado ao investimento em BIM (Building Information Modeling - conjunto de tecnologias e processos integrados que permite a criação, a utilização e a atualização de modelos digitais de uma construção, de modo colaborativo, durante todo o ciclo de vida da edificação: projeto, construção e funcionamento) e sua difusão no País (Brasil, 2019) e o Decreto $\mathrm{N}^{\circ} 10.306$ de 02 de Abril de 2020 que estabelece a utilização do BIM na execução direta ou indireta de obras e serviços de engenharia realizada pelos órgãos e pelas entidades da administração pública federal (Brasil, 2019). Instituições que monitoram o setor da construção civil no Brasil têm apresentado relatórios sobre o tema (CBIC, 2016a, 2016b, 2018; SEBRAE, 2019) e informado o grau de inovação tecnológica que vem ocorrendo no setor.

Apesar do incentivo, as pesquisas apontam que, no canteiro de obras, ainda existem problemas de comunicação (Brady et al., 2018; Leite \& Alves, 2020) e que esses avanços estão ocorrendo, em sua maioria em nível de projeto e planejamento das obras, conforme relatórios (CBIC, 2018; SEBRAE, 2019). Segundo Silva Junior, et al. (2020), no Brasil apenas $20 \%$ das empresas utilizam software para gestão de obras e 3,2\% desses usam o sistema BIM para esse fim. Portanto, na gestão de obras, apesar dos avanços em relação aos materiais e manuseio de matérias-primas (CBIC, 2016a), a falta de adesão às inovações, na gestão do canteiro de obras, ainda dificulta o trabalho eficiente.

Matta et al. (2018) evidenciam que, em canteiros de obra, existe dificuldade de interpretação dos projetos, falta de informação ou verificação de construtibilidade, pouca coordenação entre as especialidades e tempos de resposta longos, o que comprometem os prazos de execução do projeto. Dessa forma, existe dificuldade de comunicação entre os níveis tático e operacional. O trabalhador, geralmente, não sabe o que é esperado dele ou qual foi o seu desempenho na realização de suas atividades (Leite, 2014). Muitas vezes, perde tempo buscando materiais e ferramentas para a realização de suas tarefas o que pode ter como consequência a sua baixa produtividade (Formoso et al., 2002; Brady et al., 2018).

A mão de obra tem baixa escolaridade e o excesso de trabalho manual desmotiva os trabalhadores a buscarem aperfeiçoamento profissional, o que impacta diretamente em sua qualificação para o trabalho (Borges \& Peixoto, 2011). 
Portanto, ao se proporcionar melhorias para a mão de obra, estima-se uma maior produtividade das equipes, com redução de perdas, retrabalho e erros, melhorando a qualidade do processo produtivo e da edificação.

Além disso, as falhas na comunicação podem levar ao desperdício de horas de serviço, seja por ausência de demanda (hora parada), seja por retrabalho. "As construtoras geralmente possuem poucos mecanismos visuais para inspirar, instruir ou motivar os trabalhadores a realizarem suas atividades de forma mais eficaz, eficiente e segura" (Brady, 2014 p. 66). A falta de transparência no processo de construção leva a dificuldade de entendimento pelos operários e a problemas de comunicação entre os níveis tático e operacional. Tudo isso gera insatisfação e altos níveis de estresse para o trabalhador.

É nesse contexto que a inserção de elementos de jogos em contextos não-jogos (Deterding et al., 2011) aparece como uma alternativa para o ambiente de construção, no intuito de melhorar a comunicação entre gestores e a equipe de obra, com potencial de promover maior eficiência para o cumprimento das metas de produção.

Este artigo apresenta um sistema web para facilitar a comunicação entre trabalhadores e gestores no canteiro de obras a fim de melhorar o entendimento das metas de trabalhos. Trata-se de uma pesquisa exploratória, envolvendo análise de requisitos dos trabalhadores e gestores da construção civil a fim de elaborar um sistema gamificado, para futuramente subsidiar uma proposta de implantação em uma obra na cidade de Salvador-Bahia.

O presente artigo está estruturado em 5 seções, a saber: introdução, referencial teórico, metodologia, resultados e discussões, seguidos das considerações finais.

\section{Referencial Teórico}

Os tópicos a seguir estão fundamentados na revisão da literatura sobre aspectos da construção civil no Brasil, gamificação e questões éticas da gamificação no trabalho.

\subsection{A Construção Civil no Brasil: breve contexto}

No Brasil, cada vez mais, fica evidente a necessidade de monitoramento dos serviços no canteiro de obras em tempo real (Alvarez et al., 2019, Silveira et al, 2020). As informações ainda são geradas manualmente, a partir da fiscalização dos supervisores (Leite, 2018). O acesso de forma rápida, são de extrema importância para o gestor, que precisa ter controle do andamento da obra para a tomada de decisão (Brandalise et al., 2018). Os gestores precisam controlar as informações do planejamento antecipado e do planejamento semanal a fim de identificar possíveis atrasos na obra e solucionar os desvios de planejamento (Hamzeh et al., 2020). Estas informações precisam ser comunicadas a todos os envolvidos, de forma clara e eficiente a fim de evitar desperdícios de mão de obra, equipamento e material.

Os desperdícios dos insumos na construção civil representam uma preocupação para os empresários, autoridades e sociedade. Além disso, os riscos aos quais os trabalhadores da construção civil estão expostos são grandes e todos eles podem comprometer a integridade física e/ou a saúde dos operários. A indústria ainda apresenta um elevado índice de acidentes de trabalho, mesmo com a implantação de mudanças na organização dos canteiros de obras e intensificação de fiscalizações, com o cumprimento de leis e normas regulamentadoras (AEAT, 2018).

Portanto, a dificuldade de comunicação também repercute na boa orientação quanto às questões de segurança do canteiro de obras. Dessa forma, a imprudência, a não utilização de equipamento de proteção individual e a falta de comprometimento da equipe estão entre as principais causas dos acidentes de trabalho na construção civil. Dados de um levantamento realizado pela Previdência Social e pelo Ministério do Trabalho em 2018, revelaram que acontecem 576.951 acidentes de trabalho anualmente no Brasil. E, desses, 29.612 está relacionado à construção civil (AEAT, 2018). Assim, a 
busca por práticas sustentáveis depende da qualidade nos processos de gestão, bem como a preocupação com a saúde e o bemestar do trabalhador.

Para Del Fiaco (2013), a qualidade de vida no trabalho é essencial para o crescimento, tanto para as organizações, quanto para seus colaboradores, sendo necessário que as empresas valorizem a melhoria das condições de trabalho e que mantenham um padrão de relacionamento saudável. Portanto, conhecer os principais fatores que motivam e/ou satisfazem os trabalhadores pode servir como ferramenta de gestão na interpretação e entendimento do processo, bem como, para o desenvolvimento de ações que aumentem o compromisso das equipes de trabalho.

Foi visando melhores condições de trabalho e relacionamento mais saudável entre empresa e trabalhadores que surgiu a ideia de incorporar estratégias de gamificação às rotinas de trabalho da construção civil. Esse assunto será discutido na teoria sobre gamificação.

\subsection{Gamificação}

A gamificação é a utilização de mecânicas, dinâmicas e pensamento baseados em jogos no contexto da vida real, para capacitar pessoas, motivar ações, promover o aprendizado e resolver problemas (Deterding et al. 2011, Zichermann \& Cunningham, 2011; Alves et al., 2014; Kapp, 2012; Huotari \& Hamari, 2012, 2017).

É importante observar que, apesar do uso de elementos de jogos, as aplicações gamificadas, 'não são propriamente jogos' (Deterding et al. 2011). Normalmente, a 'gamificação é usada com a intenção de influenciar positivamente o comportamento humano' (Deterding, 2015; Hamari, Koivisto \& Sarsa, 2016; Morschheuser, Hamari \& Koivisto, 2016; Seaborn \& Fels, 2015). Esta influência de comportamento envolve motivação, comprometimento que resulta em aprendizado, desenvolvimento de novos hábitos, resolução de problemas e quando aplicada ao trabalho pode levar a impactos organizacionais (Huotari \& Hamari, 2017).

Petelczyc et al (2018) observam que a gamificação ganhou interesse crescente entre gerentes de mentalidade progressista como um impulsionador de motivação e produtividade em ambientes laborais. Cada vez mais as pesquisas relatam essa condição do século 21 em que diversão e trabalho fazem parte do cotidiano (Vesa, Hamari, Harviainen \& Warmelink, 2017; Vesa, Den Hond, \& Harviainen, 2018).

Deci e Ryan (2017) definem motivação como "a força que emerge, regula e sustenta as ações de cada indivíduo", e afirmam que é um processo complexo que influencia o início de uma atividade e a sua manutenção com persistência e vigor ao longo do tempo. Para os autores a motivação muda em função das características do contexto ao qual o indivíduo está exposto. Portanto quanto mais motivado estiver o trabalhador maior será o seu comprometimento com os resultados do trabalho.

Deci e Ryan (2017) desenvolveram a Teoria da Autodeterminação (Self-Determination Theory - SDT), classificando os tipos de motivação a partir das diferentes razões ou objetivos que originam uma ação. Inicialmente, os autores classificaram a motivação em dois tipos: intrínseca e extrínseca. A motivação intrínseca está relacionada à força interior que é capaz de se manter ativa mesmo diante de adversidades. Enquanto a motivação extrínseca está diretamente ligada ao ambiente, às situações e aos fatores externos.

Para facilitar a concepção de um sistema gamificado, Schlemmer (2018) apresentou a gamificação analisada sob duas perspectivas 'persuasão' e 'colaboração e cooperação'. Por persuasão Schlemmer (2018) define como uma perspectiva que estimula a competição através de pontos e recompensas também conhecida como PBL - points, badges e leaderboard ${ }^{1}$. Segundo Schlemmer (2018), essa perspectiva é mais fácil de ser encontrada por se basear em motivação extrínseca. Por isso muitos autores, tais como Chou (2015) afirmaram que os pontos, as medalhas e o quadro de ranking são importantes como

${ }^{1}$ Points, Badges e Leaderboard (PBL)- Pontos emblemas e quadro de líderes 
bônus, dependendo do contexto, porém corresponde a uma pequena fração de resultados que a gamificação pode proporcionar. A PBL é denominada por Chou (2015) como a "casca de uma experiência de jogo" porque promove apenas a motivação extrínseca. Chou (2015), criou um modelo chamado Octalsys baseado no entendimento de como a motivação humana funciona. O modelo apresenta as oito motivações básicas que induzem os jogadores a jogarem e elenca 74 técnicas de jogos (game techniques) distribuídas nas motivações básicas.

Já a colaboração e cooperação, segundo Schlemmer (2018), é instigada por missões, desafios, descobertas, empoderamento em grupo, o que do ponto de vista da educação leva a perspectiva epistemológica interacionista-construtivistasistêmica', isto é, aquela que valoriza múltiplos espaços sociais, instigando a cooperação, tem potencial para se constituir um meio para aprendizagem frente às transformações socioculturais contemporâneas.

Diferente dos ambientes educacionais, nos canteiros de obras, muitas vezes fica difícil adotar técnicas para a construção coletiva do conhecimento, devido ao baixo nível de escolaridade dos envolvidos, às questões de infraestrutura local, ao custo elevado para o desenvolvimento de uma solução e ao pouco interesse por parte dos empresários em investir. Porém, é possível inserir mecânicas e dinâmicas como narrativas, missões, itens colecionáveis, conquistas para ampliar o leque de ações proposto para uma experiência gamificada. Para isso foi necessário maior investigação do contexto da obra antes de projetar a estratégica gamificada, envolvendo assim, a compreensão da cultura dos sujeitos, do ambiente e seus objetivos como propôs Schlemmer (2018).

Chou (2019) afirmou que a maioria dos sistemas são projetados para facilitar a realização das tarefas no menor tempo possível, de forma mais prazerosa. Assim, durante a fase de concepção da gamificação, é preciso considerar que as pessoas que desempenham essas atividades têm emoções, inseguranças e opiniões a respeito do que se espera delas, ou sobre a forma como deveriam atingir seus objetivos profissionais. Portanto, a observação dos participantes em seu contexto de trabalho, da cultura local e as particularidades do ambiente são fundamentais para o sucesso da experiência gamificada.

A inserção de gamificação no trabalho é estudada por diversos autores como forma de incentivo ao alcance de metas, treinamento e diminuição do tédio nas suas rotinas (Vesa, 2021, Deterding, 2019; Bohnenberger, 2018; Burke, 2015). Na Construção Civil apenas quatro estudos relacionados ao setor foram encontrados na revisão da literatura: Morêda Neto et al. (2014), apresentam um plano de implantação de um sistema gamificado para tornar transparente as informações do planejamento semanal; Leite et al. (2016) apresentam a implantação, por três meses, de um sistema gamificado em um canteiro de obras a fim de tornar transparentes para a empresa, equipe de obra e trabalhadores as informações do planejamento semanal.

Khanzadi et al. (2019), desenvolveram e implantaram por quatro meses um sistema gamificado para aplicação de lean no planejamento e controle da produção em construções offshore e Selin et al. (2019), apresentam um método gamificado que pode ser usado para planejar a segurança dos ambientes baseados no modelo de informação (BIM).

Por fim, a gamificação com técnicas de narrativas, missões e desafios em canteiro de obras ainda não foi explorada, portanto pode ser uma solução para melhorar o entendimento dos trabalhadores em relação às suas metas, incentivá-los a cumpri-las e para criar o sentimento de pertencimento ao ambiente de trabalho através de ciclos de feedbacks.

\section{3 Ética na gamificação}

Ética pode ser definida como um conjunto de conceitos e princípios que nos guiam na determinação de qual comportamento ajuda ou prejudica criaturas sensíveis (Paul \& Elder, 2003). A questão ética é algo preocupante a ser verificado na forma de incorporar a gamificação ao trabalho. Autores como Bogost (2015), Kim (2015) e Kim (2018) discutem sobre resultados negativos das estratégias de gamificação, como manipulação e exploração dos participantes, se não forem aplicadas corretamente. Portanto, a gamificação pode ser uma ferramenta positiva para motivar os funcionários ou pode ser uma fonte de tensão e pressão, com possibilidade de afetar o bem-estar social e mental dentro o local de trabalho (Shahri et al., 2014). 
Para Chou (2019), dois requisitos são importantes para se considerar como ético um sistema gamificado: o sistema precisa ter total transparência para o que se destina e o usuário precisa consentir a participação na gamificação.

Conforme mencionado por Deterding (2019), a escolha da arquitetura da gamificação funciona como um refinamento das práticas do negócio, portanto em termos éticos é importante verificar, atentamente, como o processo funciona sem a gamificação.

As práticas de gestão na construção civil já possuem critérios éticos bem definidos e conquistados pelos próprios trabalhadores através dos acordos sindicais, estas regras não poderão ser quebradas com a inserção das estratégias de gamificação no ambiente de produção. Vale destacar que esta pesquisa está em conformidade com a Lei Geral de Proteção de Dados Pessoais, $\mathrm{n}^{\circ} 13.709$, de 14 de agosto de 2020 no que se refere a transparência, consentimento, finalidade e responsabilidade, ao conceito de dados pessoais e dados coletados para garantir respeito e transparência aos participantes. Assim, todas as estratégias incorporadas ao software foram analisadas para assegurar respeito ao operário.

A próxima seção, apoiada na metodologia de pesquisa científica, apresenta a escolha e o planejamento da estrutura de investigação para a realização da pesquisa e visa mostrar as etapas para chegar a solução desenvolvida, a fim de facilitar a comunicação entre trabalhadores e gestores no canteiro de obras para melhorar o entendimento das metas de trabalhos.

\section{Metodologia}

A abordagem metodológica Design Science foi selecionada como mais adequada para o desenvolvimento deste trabalho por ser utilizado em pesquisas cujo objetivo é criar, desenvolver e explorar novas soluções (Hevner, March \& Park, 2004) A pesquisa foi desenvolvida utilizando como método o Design Science Research que está relacionada com o desenvolvimento e avaliação de artefatos visando resolver problemas do mundo real (Dresch et al.,2015; Lacerda et al., 2013; Van Aken, 2004, Lukka, 2003).

Neste caso, trata-se de uma pesquisa exploratória, empírica, qualitativa com a finalidade de conhecer as estratégias de gamificação como mecanismo para melhorar a comunicação e a disseminação das informações de produção para os trabalhadores no canteiro de obras A pesquisa é composta de 3 fases:(1) Fase de compreensão, (2) Fase de desenvolvimento, (3) Fase de análise e avaliações, o presente artigo faz referência a fase de desenvolvimento do sistema gamificado.

A primeira fase consistiu na identificação e entendimento do problema, visando conhecer o perfil do trabalhador da construção civil. Para essa investigação elaborou-se um formulário online, com 12 questões objetivas, que foi aplicado em duas rodadas na obra $\mathrm{A}^{2}$ situada em Salvador- BA, com foco nas características gerais do público-alvo. Foram entrevistados 109 trabalhadores, 108 do sexo masculino e 1 do sexo feminino.

Para a realização desta pesquisa, solicitou-se de cada participante a assinatura do Termos de Livre Consentimento Esclarecido (TCLE) aprovado pelo Comitê de Ética em Pesquisa do IFBA, com o parecer consubstanciado de número 1.932.146 de 17 de fevereiro de 2017. Nesses termos, o participante considerou-se livre e esclarecido para consentir em participar da pesquisa proposta, resguardando aos autores do projeto a propriedade intelectual das informações geradas e expressando a concordância com a divulgação pública dos resultados.

Além da pesquisa com os trabalhadores do canteiro da obra, aliado à revisão da literatura, procurou-se também conhecer a aceitação dos engenheiros em relação à gamificação e as características básicas das obras que trabalham.

Na segunda fase, após a análise dos dados indicados acima, foram definidas as estratégias de gamificação e as implementações necessárias para o funcionamento integrado da solução. O produto desta fase foi o sistema gamificado, foco deste artigo. Portanto, após o levantamento de requisitos, da escuta dos trabalhadores e observações no canteiro de obras foi

\footnotetext{
${ }^{2}$ Para preservar a identidade da Empresa chamou-se a obra onde foi desenvolvida a pesquisa de Obra A.
} 
possível projetar uma solução, desenvolver e testar o sistema gamificado, agregando melhorias a partir dos testes e avaliações preliminares.

Foi aplicado para os testadores o System Usability Scale (SUS), criado por Brooke (2013) composto por 10 afirmações que fazem uso da escala Likert ${ }^{3}$ sendo que os questionamentos ímpares têm conotação positiva e os pares negativa. Dessa forma, para contabilizar o resultado associa-se às respostas valores de 0 a 4 , para os ímpares subtrai-se 1 do valor informado e para os pares diminui-se o resultado de 5 somando-se a todos os resultados e multiplicando-se por 2,5 para se obter um valor em percentil (Moura Junior, 2020). A classificação por aceitabilidade define os seguintes critérios: Não aceitável [0 - 49], Médio [50 - 70], Aceitável [70 - 100].

\section{Resultados e Discussão}

Os resultados dessa pesquisa estão relacionados a fase de desenvolvimento do sistema gamificado para atender aos requisitos da obra, levantados na fase anterior. Nesta seção serão apresentados a análise dos requisitos que subsidiaram o projeto do sistema, o sistema gamificação na produção e informações de como foram realizados os testes do sistema e avaliações preliminares. As discussões dos subtópicos foram realizadas a luz da literatura.

\subsection{Análise de requisitos na obra}

A amostra dos 109 trabalhadores foi escolhida aleatoriamente na obra A. A idade média dos trabalhadores foi 35,76 o que mostra uma concentração de um público na fase adulta. Quanto ao grau de escolaridade apenas 25,7 \% do público possui nível médio completo; 46,8 \% não conseguiu completar o nível fundamental, constatando-se que o nível de escolaridade do público é baixo. Esta informação é importante, pois indica que o ambiente gamificado deve ser mais icônico, evitando a leitura de textos alfabéticos e incentivando mais a leitura imagética.

Quanto à função dos respondentes, dividiu-se o público em três grupos: (1) Profissionais - são os trabalhadores que exercem as atividades de pedreiro, carpinteiro, armador, encanador e eletricista. Esta função é atingida após algum tempo de experiência bem-sucedida nas funções de auxiliar e servente. (2) Ajudante - é uma função de auxiliar dos profissionais, geralmente é exercida por trabalhadores que têm algum treinamento na função. (3) Serventes - são trabalhadores que realizam tarefas de serviços gerais na obra como, por exemplo, movimento de materiais e serviços de limpeza e arrumação do local. Participaram da pesquisa 59 profissionais, 37 ajudantes e 13 serventes.

Após a análise das entrevistas com os trabalhadores pode-se entender que: eles gostam do que fazem (96\%); a maioria mostra uma enorme carência de reconhecimento (51,4\%). Gostam de jogar (78\%), especialmente o Futebol (60\%), Cartas (7\%), Dominó (21\%) e outros (4\%). Preferem trabalhar em equipe (90\%). Todos possuem aparelhos celulares e muitos deles costumam jogar usando o smartphone ${ }^{4}(45 \%)$. Usam regularmente WhatsApp (85\%), Facebook (68\%) e Instagram (48\%). Entendem que a diversão é algo prazeroso e que faz parte do cotidiano, gostaram da ideia de gamificação e querem participar.

Ao questionar 26 engenheiros de obra, com experiência entre 5 e 35 anos de atuação em construção, sobre o uso de gamificação, acreditam que gamificar é interessante para melhorar o andamento da obra e a motivação do trabalhador (92,3\%). A maioria dos engenheiros $(96,2 \%)$ acreditam que a ideia de dar feedback aos trabalhadores é boa e que aumentaria a motivação.

Leite et al. (2016) afirmam que $60 \%$ dos trabalhadores nunca receberam feedback do cumprimento de suas metas semanais, $51,4 \%$ dos entrevistados demonstram uma enorme carência de reconhecimento. Assim, concluiu-se que os

${ }^{3}$ Escala Likert - é um tipo de escala de resposta psicométrica usada habitualmente em questionários para medir opinião

${ }^{4}$ Smartphone-Telefone celular com tecnologias avançadas, o que inclui programas executados e um sistema operacional, equivalente aos computadores. 
trabalhadores da construção civil sentem uma enorme necessidade de reconhecimento causada ela ausência de feedback e pelas dificuldades de comunicação com a gestão da obra. Isso se deve, também, à forma dinâmica como ao atividades acontecem tornando o trabalho repetitivo e enfadonho. Maiores detalhes da pesquisa exploratória (primeira fase) encontram-se publicados em Leite e Alves (2020).

De acordo com o levantamento de requisitos realizado na obra, as necessidades do usuário eram: (1) Explicitação das metas semanais e dos serviços das equipes; (2) Feedback ${ }^{5}$ às equipes de serviços e (3) Feedback ao trabalhador de forma privada para evitar a exposição desnecessária do profissional. Tudo isso a fim de melhorar a comunicação no canteiro de obras e incentivar o trabalhador, tornando o ambiente mais colaborativo. A partir dos requisitos, elaborou-se os casos de uso apresentados na Figura 1.

Figura 1. Casos de uso do Sistema Gamificação na Produção.

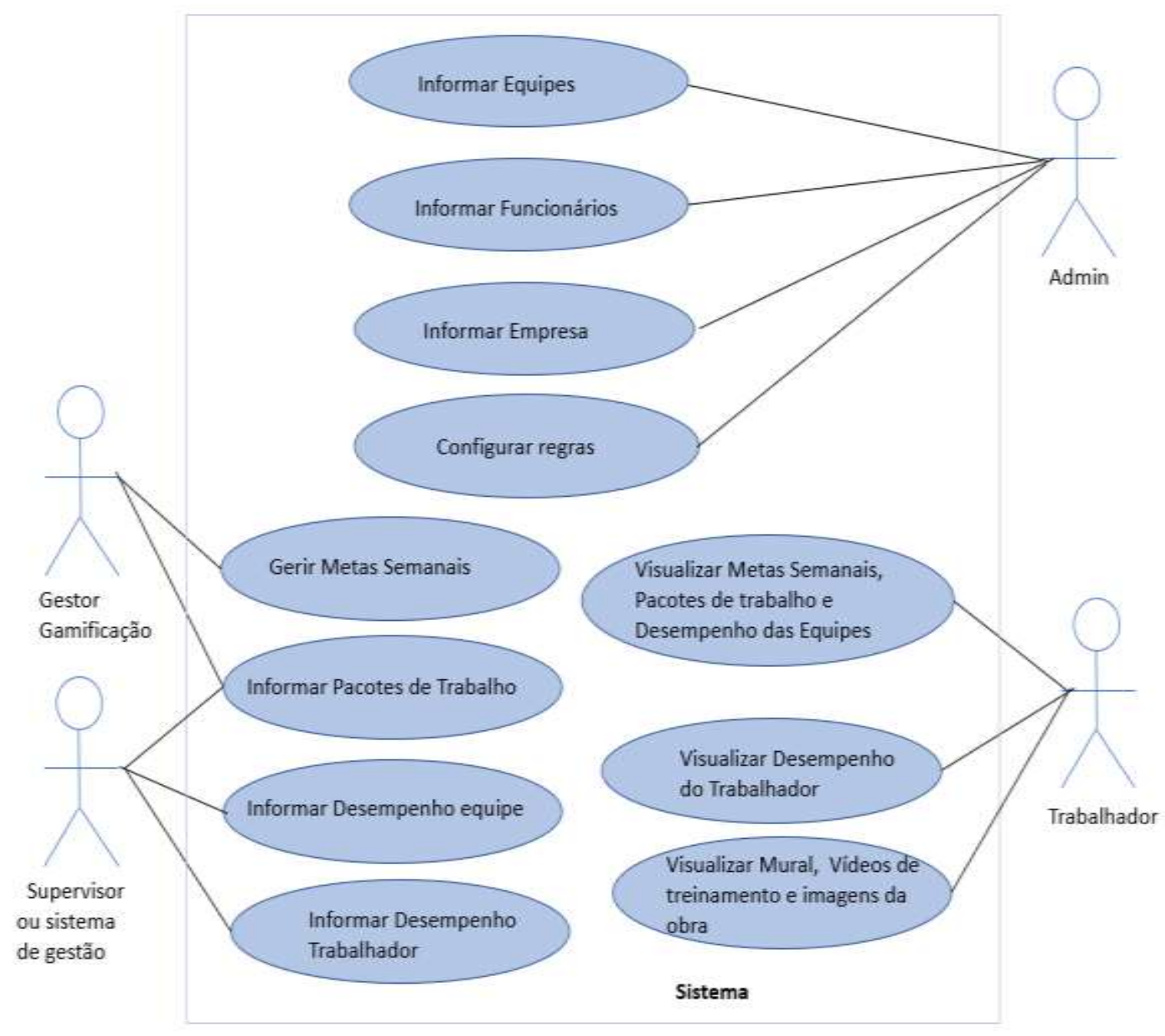

Fonte: Autores.

Para viabilizar a explicitação das metas semanais, o sistema deverá ficar visível na obra, em local estratégico para evitar distrações, através de um monitor de 32”. O gestor do processo, que pode ser um estagiário, informará as metas semanais, postará vídeos para treinamento para o trabalhador e escolherá imagens da obra como plantas-baixas, detalhes de

${ }^{5}$ Feedback - retorno construtivo sobre o desempenho de um profissional 
projetos e/ou representações em 3D, relativas à semana de trabalho. O sistema foi pensado para inserção manual ou para ser integrado aos sistemas de gestão utilizado pela obra.

$\mathrm{O}$ andamento das tarefas (avanço do serviço), o desempenho das equipes e dos trabalhadores será alimentado por um supervisor, durante sua fiscalização, através de um tablet ou celular no canteiro de obras ou por sistema existente, assim ficarão explicitados para todos os participantes da obra. Segundo Valente (2017), a comunicação por meio de dispositivos visuais tem sido cada vez mais frequente nos canteiros de obras, tornando a gestão visual uma importante estratégia de comunicação de curto alcance com base na veiculação de informações de forma cognitivamente mais eficiente.

Para promover a colaboração no canteiro de obras, a gamificação foi pensada com atividades em grupo, a fim de motivar os trabalhadores a realizarem as suas metas dentro do prazo. Futuramente, na época da implantação, serão definidas regras com os gestores da obra e atribuídos pontos a cada regra estabelecida. Durante cada semana de gamificação também serão combinados com os gestores da obra, desafios e missões que deverão ser realizadas pelas equipes de trabalhadores.

A interface gamificada usará como metáfora um campeonato de futebol, visto que a $60 \%$ dos trabalhadores mencionaram que gostam deste esporte. Para Busarello (2016) existem três elementos-chave que tornam os sistemas baseados em jogos artefatos motivacionais: o desafio, a metáfora (fantasia) e a curiosidade.

A metáfora define um ambiente que promove situações - cognitivas, físicas ou sociais, que não existem. As metáforas proporcionam experiências emocionantes, pois são incorporados no ambiente objetos e situações estimulando o imaginário do sujeito (Busarello, 2016). A Figura 2 apresenta exemplos de regras, formas de respostas do sistema, recompensas e práticas colaborativas que o sistema gamificado permite adotar.

Entende-se que práticas colaborativas são formas de unir pessoas para contribuir igualitariamente em um ambiente favorável, de acordo com as vivências individuais, estreitando os laços sociais, enfrentando situações e desafios existentes com o objetivo de solucioná-los em grupo (Moura Júnior, 2020).

Figura 2. Regras, resposta, recompensas e práticas colaborativas.

\begin{tabular}{|c|c|c|c|c|}
\hline & Regras & Resposta do sistema & Recompensas & Práticas Colaborativas \\
\hline$\frac{\pi}{3}$ & $\begin{array}{l}\text { Atividades semanais regulares } \\
\text { Ex: Produção } \\
\text { Qualidade } \\
\text { Cronograma } \\
\text { Segurança } \\
\text { Desafios -Atividades pontuais } \\
\text { Ex: Pergunta sobre assunto importante para a } \\
\text { obra ( Desafio educativo) } \\
\text { Missões - Atividades com prazo de } \\
\text { entrega } \\
\text { Ex: } 5 \text { S no local de trabalho ( prática que } \\
\text { pode se transformar em hábito) }\end{array}$ & $\begin{array}{l}\text { Através de simbolos e } \\
\text { cores que facilitem o } \\
\text { entendimento do } \\
\text { trabalhador. Ex.: }\end{array}$ & $\begin{array}{l}\text { Pontos } \\
\text { Troféus } \\
\text { Crachás } \\
\text { Palmas no horário da } \\
\text { reuniāo semanal } \\
\text { Tocar a musica do time } \\
\text { preferido } \\
\text { Elogio ao trabalho da } \\
\text { equipe }\end{array}$ & $\begin{array}{l}\text { Metas, missões e desafios a } \\
\text { serem cumpridos em equipe } \\
\text { Narrativa: Campeonato de } \\
\text { Futebol, onde cada equipe } \\
\text { representará um time }\end{array}$ \\
\hline 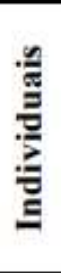 & $\begin{array}{l}\text { Atitudes desejáveis ou obrigatórias no } \\
\text { canteiro de obras. Ex: } \\
\text { Uso de EPI } \\
\text { Pontualidade } \\
\text { Retirada e devolução de ferramentas } \\
\text { Participação na reunião semanal }\end{array}$ & $\begin{array}{l}\text { Através de simbolos e } \\
\text { cores que facilitem o } \\
\text { entendimento do } \\
\text { trabalhador. Ex. } \\
\end{array}$ & $\begin{array}{l}\text { Mensagem positiva ao } \\
\text { trabalhador }\end{array}$ & $\begin{array}{l}\text { Resposta do sistema positiva } \\
\text { a fim de estimular o } \\
\text { desempenho para colaborar } \\
\text { com a equipe }\end{array}$ \\
\hline
\end{tabular}

Fonte: Autores. 
Além das informações explicitadas no monitor sobre metas e desempenho das equipes, o trabalhador receberá em seu smartphone, através do WhatsApp, um link de acesso ao sistema com informações sobre o seu desempenho individual semanal e mensagens positivas de motivação. Para Busarello (2016) feedbacks positivos de falhas motivam o indivíduo a continuar tentando realizar determinado desafio, aumentando o nível de envolvimento com a tarefa.

As estratégias propostas neste sistema são: pontos, avatares, narrativa, desafios, missões e outros mecanismos de jogos visando incentivar o trabalhador. Para Chou (2019) a utilização de elementos de gamificação contribui para o despertar de sensações no sujeito através da vivência de uma experiência de forma intensificada. Desta forma, em relação ao desempenho individual, por questão éticas, somente o trabalhador conhecerá o seu, diferenciando nesse aspecto do modelo PBL.

\subsection{O Sistema Gamificação na Produção}

Para a implementação do sistema gamificado, analisou-se os requisitos, elaborou-se projeto e implementou-se o sistema web em linguagem Python, escolhida para o desenvolvimento por ser robusta e fácil de usar ${ }^{6}$. Optou-se pelo sistema web por ser mais fácil de acessar, através do wifi da obra, pelo público-alvo (trabalhadores), do que aplicativos que necessitam de memória para serem instalados no celular. O processo de produção do sistema web foi realizado por um desenvolvedor externo que utilizou da metodologia ágil, Scrum para o desenvolvimento de software. O Scrum tem como características intrínsecas a flexibilidade e a rapidez nas respostas a mudanças (Brito \& Vieira, 2017). Nesse processo, a participação da pesquisadora principal deste artigo foi de validação do sistema, dando feedbacks, subsidiando a produção. Desta forma, destaca-se que a pesquisa como um todo não utilizou esta metodologia.

A primeira tela do sistema é uma tela de apresentação (Home) que foi concebida para funcionar como um mural, podendo suportar a divulgação de regras para a gamificação antes da implantação na obra e avisos relativos ao processo, que porventura sejam necessários.

A segunda tela mostrada na Figura 3, apresenta as metas semanais. Possui uma tabela com os times, a descrição dos serviços e a meta para a semana, chamada no sistema de rodada para criar uma conexão com o campeonato de futebol, neste exemplo se refere à $5^{\text {a }}$ rodada. A informação ‘Chutes a gol' se refere ao quanto da meta já foi cumprido, porém para melhorar o entendimento do trabalhador, em vez de mostrar em percentual de avanço, este é transformado em valor de medida. Ex.: 200 de $250 \mathrm{~m} 2$ corresponde a $80 \%$ de avanço. À medida que o supervisor entrar com informações do avanço dos serviços, a célula destinada ao valor de chutes a gol vai alterando a cor: vermelho - até 50\% do serviço realizado, amarelo - entre 51 e $90 \%$ e verde - de 91 a 100\%. Esta regra é válida para todas as telas do sistema.

${ }^{6}$ Sistema gamificado desenvolvido por Eliakin Costa de Almeida experiente sistemas usando a linguagem Python. 
Figura 3 - Metas Semanais.

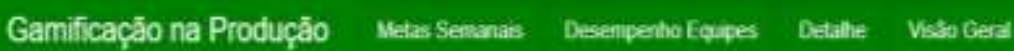

\section{Metas Semanais de 1 de Outubro de 2020 até 9 de Outubro de 2020 - Rodada 5}
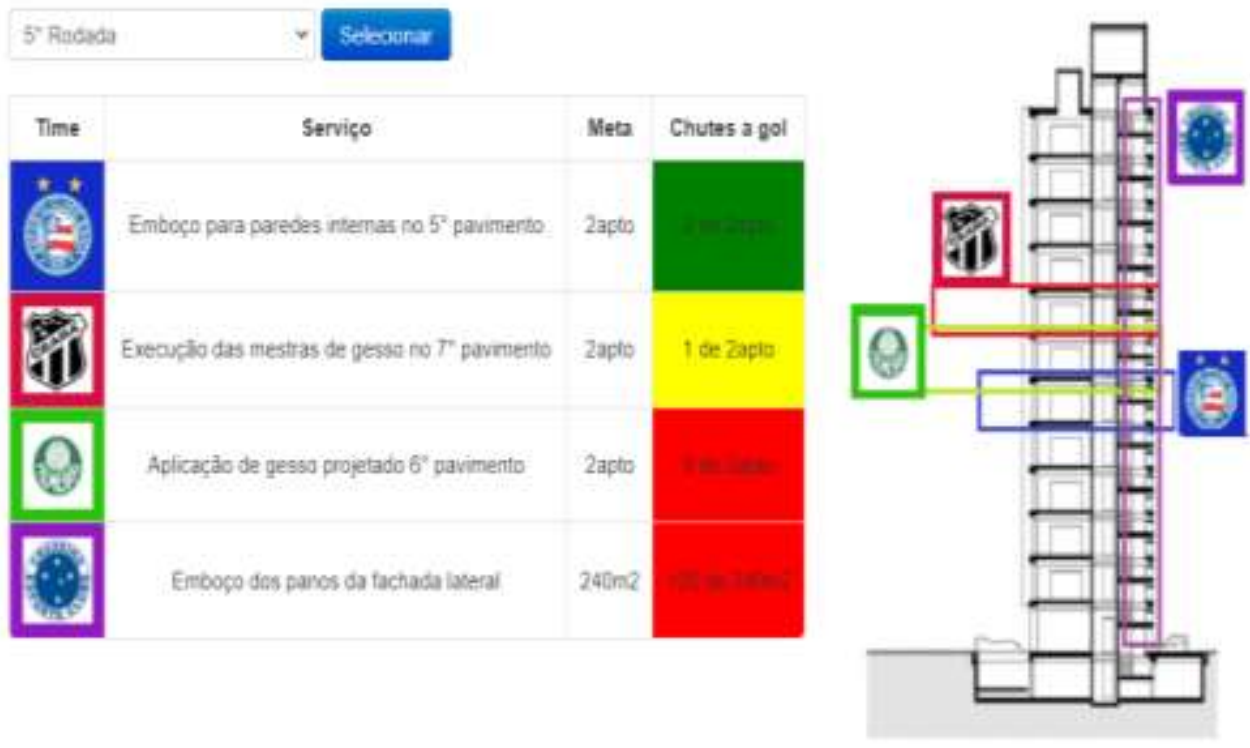

Fonte: http://gameficacao-na-producao.herokuapp.com/ (Tela configurada pelos autores a partir de imagens de domínio público)

Uma imagem indicando o local onde as equipes estão trabalhando é mostrado no lado direito da tela, pode ser um corte, em caso de obras verticais, uma planta ou ainda uma imagem 3D que possa explicitar de forma clara quais as metas da semana. Essa tela também permite que se consulte o que ocorreu nas rodadas anteriores e, para cada rodada, apresenta uma imagem informando onde as equipes executam os serviços, o que pode contribuir para se ter um histórico dos serviços realizados. O sistema não possui limitação de linhas por tela, porém, para facilitar a análise das informações do processo de gamificação, apenas quatro serviços foram escolhidos.

A gamificação foi desenvolvida inspirada no Campeonato Brasileiro de Futebol - Brasileirão. Os clubes correspondem às equipes de trabalhadores. A temporada, que no Brasileirão ocorre de abril a dezembro de cada ano, possui prazos configuráveis a critério da gestão da obra. Isso porque, a depender da etapa da obra, ocorrem mudanças de equipes e novos serviços, o que descaracterizaria o campeonato. As rodadas, assim como no Brasileirão, correspondem a uma semana, o que coincide com a programação de curto prazo da obra.

A Figura 4 mostra a tela de desempenho dos times. Neste exemplo foram criadas regras com nomes de Segurança, Qualidade, Prazo e Produção, que são metas relacionadas ao serviço realizado pela equipe e pode assumir os status representados pelos ícones já explicados anteriormente. 
Figura 4 - Desempenho dos Times
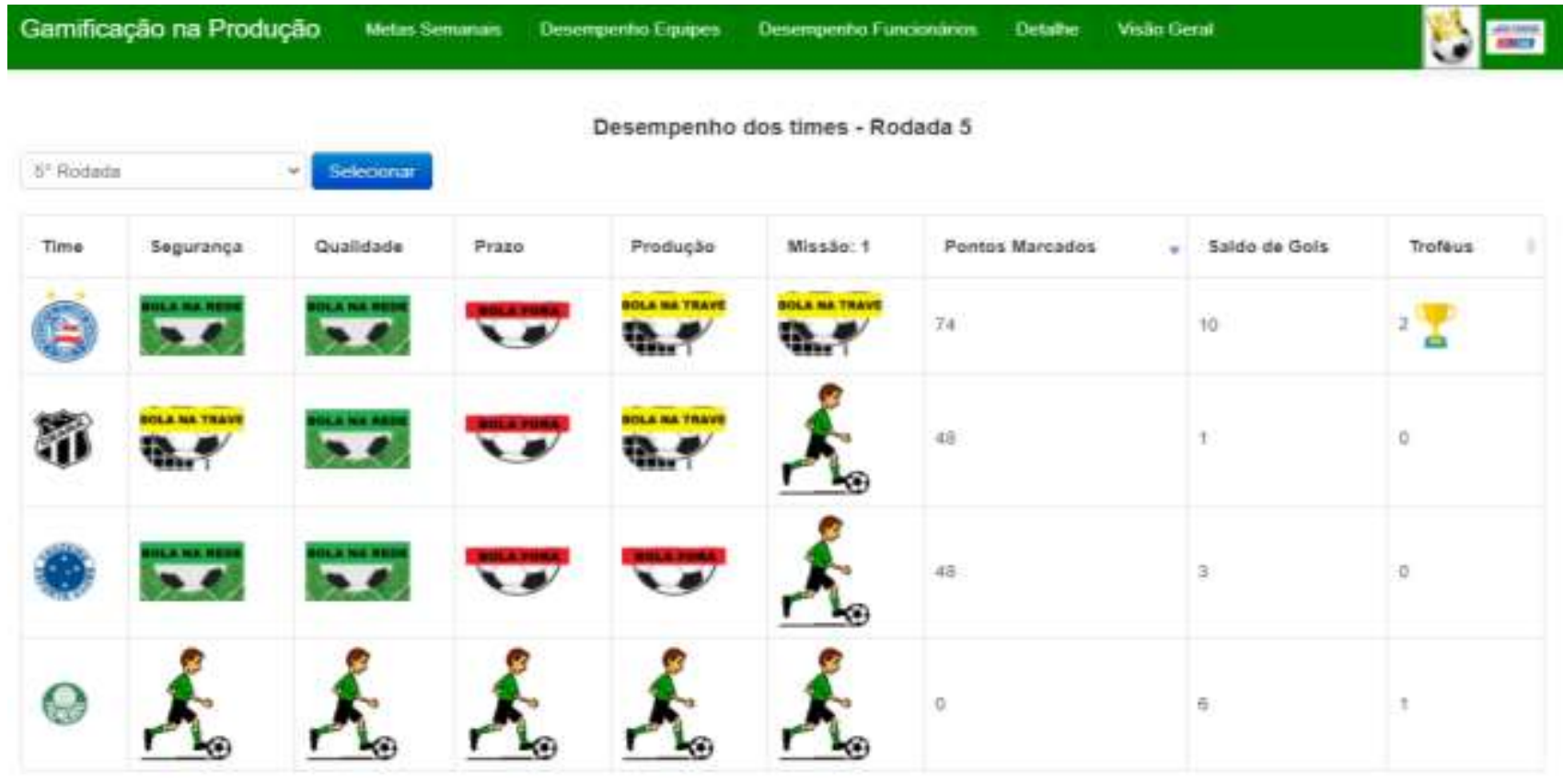

Fonte: http://gameficacao-na-producao.herokuapp.com/ (Tela configurada pelas autoras a partir de imagens de domínio público).

A missão e o desafio podem ocorrer paralelamente ou apenas um deles. A equipe não deve ser obrigada a participar da gamificação e se estiver participando pode optar por não participar da missão ou do desafio semanal. Assim, toda vez que não houver participação ou resultado, o gif de jogador correndo atrás da bola aparecerá na tela.

No Brasileirão, as equipes recebem três pontos por vitória e um por empate. Não são atribuídos pontos para derrotas. No Sistema Gamificação na Produção, essa pontuação é flexível e pode ser estipulada pela equipe gestora da obra. O sistema foi construído visando enfatizar mais a superação da equipe do que a competição. No exemplo mostrado, foram atribuídas as seguintes pontuações: bola na rede - 20 pontos; bola na trave - 12 pontos e bola fora - 4 pontos. Portanto, mesmo não tendo cumprido a meta semanal, a equipe pode ganhar pontos.

Da mesma forma que ocorre no Brasileirão, as equipes são classificadas em cada rodada pelo total de pontos marcados, porém, aqui, apenas o saldo de gols determinará o ganhador da temporada. A quantidade de vezes que a equipe atingiu o status 'bola na rede' são contabilizadas no saldo de gols e no final do campeonato vence aquela que conseguir o maior saldo de gols. Em cada rodada, no caso de empate todos recebem troféus e estes serão acumulados ao longo da temporada.

Para exemplificar o feedback individual foi criado um trabalhador fictício chamado Felipe, que recebeu o seu link privado pelo WhatsApp para acessar as informações relativas ao seu desempenho individual conforme a Figura 6. Observe que o trabalhador também tem acesso às outras funcionalidades do sistema pelo smartphone.

Na Figura 5, o círculo à direita é um emblema com o número de pontos que o trabalhador atingiu na rodada. Neste exemplo, o trabalhador Felipe fez 14 dos 25 pontos da rodada. Abaixo uma imagem com uma mensagem positiva (obtida nas imagens públicas) e rolando a tela é possível ver o desempenho em cada regra da rodada. As regras valem, no máximo, 5 pontos cada, atribuídos da seguinte forma: 0 ou 1 - 'carinha vermelha' (emoji triste); 2 ou 3 - 'carinha amarela' (emoji neutra) e 4 ou 5 - 'carinha verde' (emoji feliz). 
Optou-se por acesso individual à tela de desempenho dos trabalhadores para que ele não fique exposto às críticas dos colegas, criando um clima de competição. O feedback individual não deve promover a competição entre os participantes, é apenas para comunicar ao trabalhador, de forma positiva, que ele ainda pode melhorar se ficar mais atento à regra em que obteve "carinha vermelha".

Figura 5 - Desempenho dos Trabalhador através do link privado.

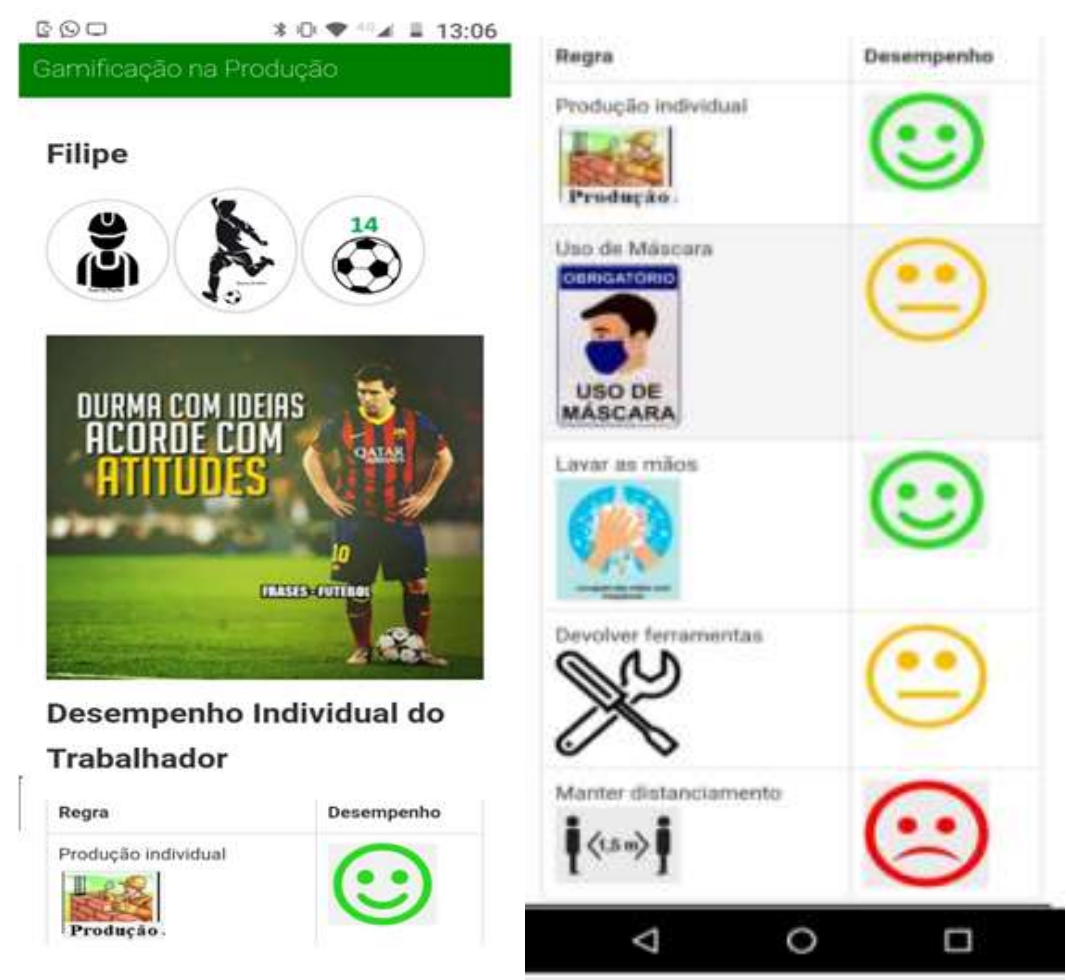

Fonte: http://gameficacao-na-producao.herokuapp.com/ (Tela configurada pelas autoras a partir de imagens de domínio público)

Ao longo de estudos sobre treinamentos gamificados, surgiu a ideia de disponibilizar no sistema uma tela que possibilite a visualização de vídeos, para treinamentos curtos. (Figura 6). 
Figura 6 - Detalhe.

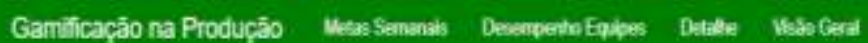

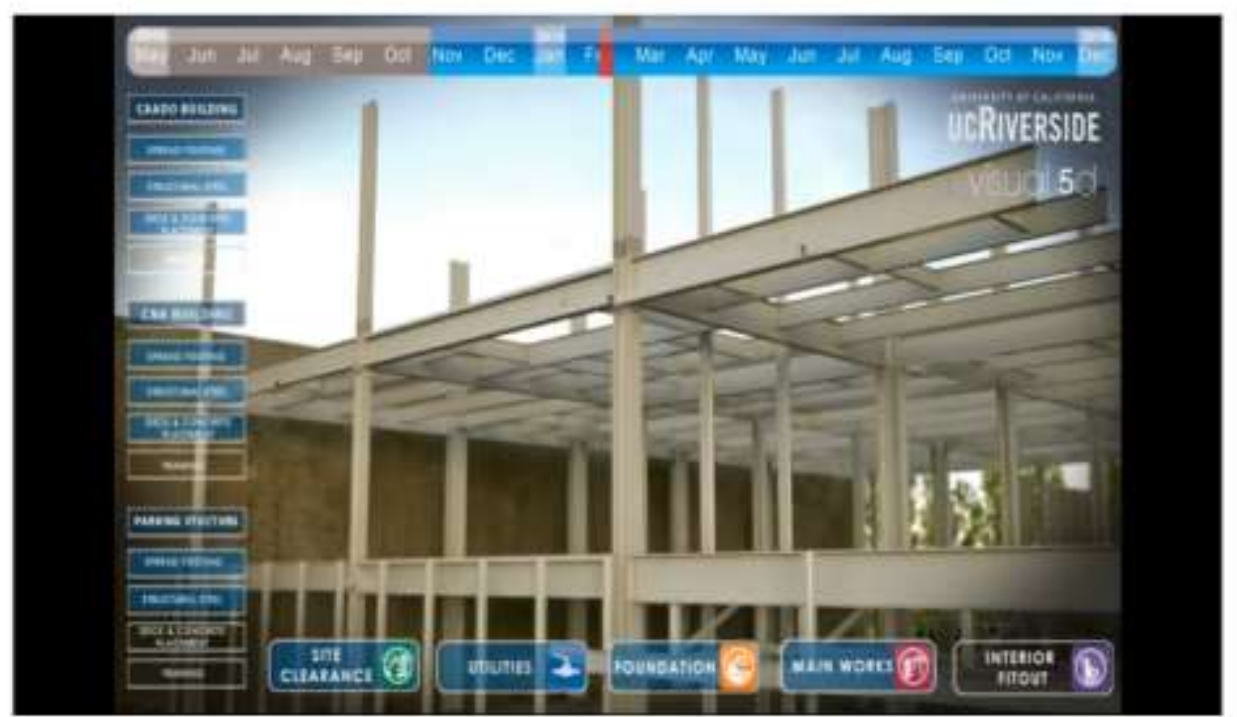

Fonte: http://gameficacao-na-producao.herokuapp.com/ (Tela configurada pelas autoras a partir de imagens de domínio público)

É possível fazer simulações das etapas da construção ou do detalhe construtivo com o uso de ferramentas BIM (Building Information Modeling). Essas simulações podem ser compartilhadas através de vídeo (formato avi), fotos (formato jpg). Assim, o trabalhador pode ser capacitado a realizar o serviço, no próprio local de trabalho. Outros vídeos também podem ser exibidos através desta funcionalidade, como: sequências de montagens de fôrma, determinação do menor caminho para percorrer no canteiro de obras e diversas possibilidades a depender da etapa da obra.

A Figura 7 mostra a funcionalidade Visão geral, que permite visualizar a planta-baixa do canteiro de obras ou a planta-baixa do pavimento tipo que está em execução, tornando-se um importante recurso para os usuários do sistema terem acesso imediato a esta informação. 
Figura 7 - Visão Geral.

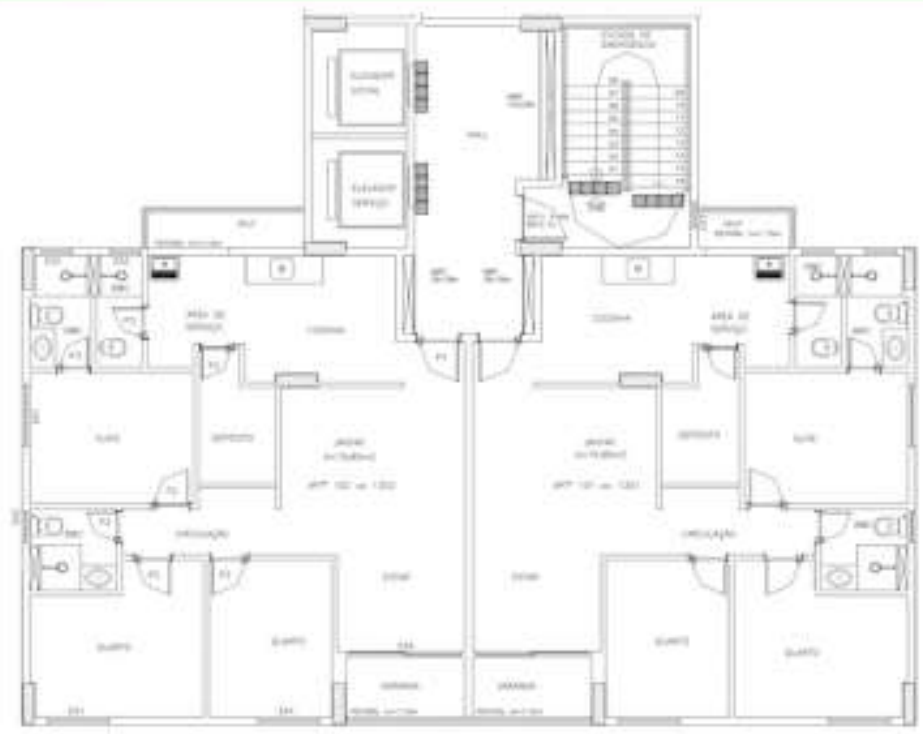

Fonte: http://gameficacao-na-producao.herokuapp.com/ (Tela configurada pelas autoras a partir de imagens de domínio público)

Com exceção da tela de Desempenho do Trabalhador, todas as outras telas do sistema podem ser mostradas no monitor para apresentar informações importantes para o andamento dos serviços no canteiro de obras. Portanto, o gestor da gamificação poderá utilizá-las de acordo com a necessidade da obra. Além disso, todas as telas podem ser acessadas pelo operário através de seu smartphone, tornando a informação disponível ao usuário em qualquer momento que ele precisar atendendo ao princípio da transparência proposto por Koskela (1992).

\subsection{Teste do sistema gamificado}

Os dados utilizados nos testes são reais, foram de uma obra já concluída. O plano semanal usado é de uma edificação vertical de fino acabamento com dois apartamentos por andar, que estava em fase de acabamento. A partir do planejamento da obra foram selecionados quatro serviços para facilitar a análise dos resultados, são eles: (1) Emboço nas paredes internas que consiste na aplicação de argamassa nas paredes internas de cada pavimento, para posteriormente revestir da edificação mostrada nas imagens com porcelanato ou cerâmica; (2) Execução das mestras de gesso que é uma preparação da parede para aplicação do gesso projetado; (3) Aplicação de gesso projetado nas paredes que posteriormente receberiam pintura e (4) Emboço nas fachadas, revestimento externo das fachadas que se encontravam na alvenaria, preparando para receber as pastilhas ou pintura externa do edifício.

Os testes aconteceram simulando seis semanas consecutivas com dados reais do planejamento. Foram realizados pela pesquisadora, a fim de seguir as regras já mencionadas anteriormente. Ao longo do processo de construção do software os testes foram feitos em três etapas, a saber: Inicialmente foi testada a tela de metas semanais, em seguida a tela de desempenho das equipes, por último a tela de dos trabalhadores. Estando pronta essa parte essencial, fez-se o teste completo do sistema e decidiu-se incluir as telas da Figura 6 e 7. Devido à pandemia, o processo como todo demorou seis meses entre o início do desenvolvimento e o final dos testes.

Fez-se uma avaliação preliminar do sistema com 10 testadores através formulário intitulado 'Questionário para testadores' que foi enviado para pessoas que conhecem a rotina do canteiro de obras, mas não atuam na área. A amostra foi composta por: 1 estudante do curso técnico em edificações (IFBA), 3 estudantes de graduação em engenharia civil (UFBA), 2 
administradores de empresas de construção civil e 4 engenheiros da área de projetos de empresas de construção civil. Com faixa etária e nível de escolaridade variados predominando as respostas de pessoas jovens [20 a 35 anos].

O questionário refere-se à ferramenta System Usability Scale (SUS)que verifica a usabilidade do sistema e é composta de 10 afirmações que o respondente deve informar, na escala de 0 a 4 o nível de concordância, como foi explicado na metodologia. Assim, através desta ferramenta, contabilizadas as médias, chegou-se a um valor igual a 61, o que se pode concluir que a aceitabilidade desse público é média [50-70]. Na opinião deste público o sistema pode ser melhorado. Eles fizeram alguns comentários e sugestões expressa nas falas dos testadores em relação à interface:

"O sistema é fácil de manusear e muito produtivo."

"Não vejo nada errado é só implantar."

"Acho a ideia do sistema de gamificação uma ótima forma de dinamizar e incentivar o entrosamento da equipe, porém a formatação apresentada no site (acessado pelo computador) foi muito confusa, e pode-se trabalhar para que seja visualmente mais atrativo (e se atentar ao choque entre cores, principalmente as que representam diferentes equipes). A atual forma de apresentação não é intuitiva, logo senti a falta de legendas. Foi muito difícil entender o que estava sendo apresentado sem nenhum tipo de fundamentação prévia. Todos os problemas que eu vi, a princípio, foram de apresentação. A ideia é interessante, mas essa parte precisa ser polida um pouco"

"Melhorar layout do sistema, facilitando o entendimento do usuário. Sugestão: Inserir texto na página inicial, com um exemplo. No mais, interessante, motivador e lúdico para os participantes."

"Acredito que pode melhorar o visual para que a interação seja mais natural, e a visualização mais atrativa."

"A paleta de cores é um pouco desconectada entre si, em alguns momentos cansa, mas a lógica é bem estruturada." Estas sugestões serão analisadas e implementadas no sistema posteriormente para melhorar a usabilidade.

\section{Considerações Finais}

O presente artigo teve como objetivo apresentar um sistema para disseminar as informações de produção para os trabalhadores da construção civil. Para fundamentar essa proposta realizou-se uma pesquisa de campo com 109 trabalhadores de onde foi possível estabelecer um perfil do público-alvo a fim de idealizar a gamificação no canteiro de obra para tornar mais transparentes as metas semanais, facilitar o entendimento do trabalhador e dar feedback dos trabalhos das equipes e individuais.

Esta pesquisa contribui para o desenvolvimento dos temas gamificação na produção, ética na gamificação e para a melhoria contínua do canteiro de obras a fim de proporcionar um ambiente mais integrado e seguro para a realização do trabalho, estabelecendo uma comunicação mais efetiva dos gestores com a força de trabalho.

Assim o sistema gamificado pode contribuir para: disseminação dos planos de trabalho para as equipes com o acesso às informações das metas semanais, andamento dos serviços diariamente e da localização das equipes de produção no canteiro de obras; reduzir o ruido na comunicação entre os participantes do processo de produção (gerentes, mestre de obras, encarregados e operários), deixando a informações mais claras para os envolvidos. Oferecer feedback do desempenho das equipes e dos operários, através das estratégias de gamificação e proporcionar qualificação dos trabalhadores, no próprio local de trabalho, através da exposição de vídeos que podem ser utilizados para esse fim.

A próxima fase desta pesquisa inclui a avaliação do sistema com um grupo de engenheiros, operários da construção civil, a fim de validar o produto. Portanto, a partir da ferramenta gamificada desenvolvida com os elementos de jogos como metas, pontos, regras, avatares usando como metáfora um campeonato de futebol, será possível verificar a aceitação do 
público-alvo para implantação do processo de gamificação, no canteiro de obras, com missões, desafios e feedback de desempenho para as equipes e aos trabalhadores.

\section{Referências}

AEAT (2018) Anuário de Estatísticas de Acidentes do Trabalho http://www3.dataprev.gov.br/aeat/

Aken, J. (2004). Management research based on the paradigm of the design sciences: the quest for field-tested and grounded technological rules. Journal of management studies, 41(2), 219-246.

Álvares, J., \& Costa, D. (2019). Construction progress monitoring using unmanned aerial system and 4D BIM. In Proceedings of the 27th Annual Conference of the International. Grupo para Construção Enxuta (IGLC), Dublin, Irlanda, 1445-1456.

Bascoul, A., Tommelein, I. \& Douthett, D. (2020). Visual Management of Daily Construction Site Space Use. Frontiers in Built Environment, 6, 139.

Bogost, I. (2015). Why gamification is bullshit. In S. P. Walz \& S. Deterding (Eds.), The gameful world: Approaches, issues, applications 65-80. MIT Press.

Bohnenberger, H. (2018). Inserção de aplicativos e gamificação nos processos de gestão (Dissertação de Mestrado, Escola Superior de Tecnologia e Gestão do Instituto Politécnico de Leiria).

Borges, L., \& Peixoto, T. (2011). Ser operário da construção civil é viver a discriminação social. Revista Psicologia: Organizações e Trabalho, 11(1), 21-36.

Brady, D. (2014). Using visual management to improve transparency in planning and control in construction (Doctoral dissertation, University of Salford).

Brady, D.., Tzortzopoulos, P., Rooke, J., Formoso, C., \& Tezel, A. (2018). Improving transparency in construction management: a visual planning and control model. Engineering, Construction and Architectural Management, 25(10), 1277-1297.

Brandalise, F., Valente, C., Viana, D., \& Formoso, C. (2018). Understanding the effectiveness of Visual Management best practices in construction sites. In Proc. 26th Annual Conference of the International. Group for Lean Construction (IGLC), González, VA (ed.), Chennai, India, $754-763$.

BRASIL. Decreto $\mathrm{N}^{\circ} 10.306$ de 02 de abril de 2020. Estabelece a utilização do Building Information Modelling na execução direta ou indireta de obras e serviços de engenharia realizada pelos órgãos e pelas entidades da administração pública federal, no âmbito da Estratégia Nacional de Disseminação do Building Information Modelling - Estratégia BIM BR, instituída pelo Decreto n 9.983, de 22 de agosto de 2019. Brasília, DF, 2020, 05 p.

BRASIL. Decreto $N^{\circ} 9.983$ de 22 de agosto de 2019. Dispõe sobre a Estratégia Nacional de Disseminação do Building Information Modelling e institui o Comitê Gestor da Estratégia do Building Information Modelling. Brasília, DF, 2019, 04 p.

BRASIL. Lei $n^{\circ}$ 13.709, de 14 de agosto de 2020. Lei Geral de Proteção de Dados Pessoais (LGPD). https://www.planalto.gov.br/ccivil_03/_ato20152018/2018/lei/113709.htm.

Brito, A., \& Vieira, J. (2017). '2TScrum' A Board Game to Teach Scrum. In Proceedings of the 31st Brazilian Symposium on Software Engineering (pp. 279288).

Brooke, J. (2013). SUS: a retrospective. Journal of usability studies, 8(2), 29-40.

Burke, B. (2015). Gamificar: como a gamificação motiva as pessoas a fazerem coisas extraordinárias. DVS Editora.

Busarello, R. (2016). Gamification: princípios e estratégias. Pimenta Cultural.

CBIC - Câmara Brasileira Da Construção Civil. (2016). 10 motivos para evoluir com o BIM. CBIC 2016.

CBIC - Câmara Brasileira Da Construção Civil. (2016). Catálogo de inovação na construção civil. CBIC 2016.

CBIC - Câmara Brasileira Da Construção Civil. (2018). Road Show BIM Resultados da pesquisa e desdobramentos. CBIC, 2018.

Chou, Y. (2015). Octalysis: Complete gamification framework. 22.

Chou, Y. (2019). Actionable gamification: Beyond points, badges, and leaderboards. Packt Publishing Ltd.

Del Fiaco, J., de Araújo, C., Souza, M., \& de Almeida Mota, M. (2013). Qualidade de Vida no Trabalho: Um estudo de caso numa empresa de contabilidade em Anápolis/GO. Revista Gestão, Inovação e Negócios, (5), 72-89.

Deterding, S. (2015). The lens of intrinsic skill atoms: A method for gameful design. Human-Computer Interaction, 30(3-4), 294-335.

Deterding, S. (2019). Gamification in management: Between choice architecture and humanistic design. Journal of Management Inquiry, 28(2), 131-136.

Deterding, S., Sicart, M., Nacke, L., O'Hara, K., \& Dixon, D. (2011). Gamification. using game-design elements in non-gaming contexts. In CHI'11 extended abstracts on human factors in computing systems (pp. 2425-2428). ACM.

Dresch, A., Lacerda, D., \& Júnior, J. (2015). Design science research: método de pesquisa para avanço da ciência e tecnologia. Bookman Editora.

Formoso, C., Santos, A. \& Powell, J. (2002). An exploratory study on the applicability of process transparency in construction sites. Journal of Construction Research, 3(01), 35-54. 
Hamari, J., Koivisto, J., \& Sarsa, H. (2014). Does Gamification Work? A Literature Review of Empirical Studies on Gamifi cation. 47th Hawaii International Conference on System Sciences (HICSS 2014) (pp. 3025-3034).

Hamzeh, F., Ezzeddine, A., Shehab, L., Khalife, S., El-Samad, G., \& Emdanat, S. (2020). Early warning dashboard for advanced construction planning metrics. In Construction Research Congress 2020: Project Management and Controls, Materials, and Contracts (pp. 67-75). Reston, VA: American Society of Civil Engineers.

Hevner, A. R., March, S., Park, J., \& Ram, S. (2004). Design science in information systems research. MIS quarterly, 75-105.

Huotari, K., \& Hamari, J. (2012). Defining gamification: a service marketing perspective. In Proceeding of the 16th international academic MindTrek conference (pp. 17-22). ACM.

Huotari, K., \& Hamari, J. (2017). A definition for gamification: anchoring gamification in the service marketing literature. Electronic Markets, 27(1), 21-31.

Júnior, M. (2020) Práticas colaborativas gamificadas para Prevenir Lesões por Pressão. Universidade Federal da Bahia (Tese do Doutorado Multidisciplinar e Multi-institucional em Difusão do Conhecimento (DMMDC).

Kapp, K. (2012). The gamification of learning and instruction (p. 93). Wiley.

Kim, T. (2015), “Gamification ethics: Exploitation and manipulation. In Gamifying research workshop papers” In Proceedings of the CHI 2015.

Kim, T. (2018). Gamification of labor and the charge of exploitation. Journal of Business Ethics, 152(1), 27-39. doi:10.1007/s10551-016-3304-6

Koskela, L. (1992). Application of the new production philosophy to construction (Vol. 72). Stanford university.

Lacerda, D., Dresch, A., Proença, A., \& Antunes Júnior, J. (2013). Design Science Research: método de pesquisa para a engenharia de produção. Gestão \& produção, 20, 741-761.

Leite, R. (2014) Uso da Gameficação para Melhoria do Planejamento e Controle de Obras. (Dissertação de Mestrado) Universidade Federal da Bahia

Leite, R., \& Alves, L. (2020). A Gamified Model for the Building Site: A Solution to Motivate Construction Wokers in Pandemic Time. Journal of Bioengineering and Technology Applied to Health, 3(4), 319-327.

Lukka, K. (2003). The constructive research approach. Case study research in logistics. Publications of the Turku School of Economics and Business Administration, Series B, 1(2003), 83-101

Mariz, R., Galvao, E., Picchi, F., Melo, R., \& Barcelos, M. (2019). Daily management application in a dam construction project. 27th Annual Conference of the International Group for Lean Construction, IGLC 2019 (pp. 1425-1434).

Matta, G., Valencia, R.., Baladrón, C., Giménez, Z., \& Alarcón, L. (2018). Using BIM-based sheets as a visual management tool for on-site instructions: a case study. 26th Annual Conference of the International Group for Lean Construction: Evolving Lean Construction Towards Mature Production Management Across Cultures and Frontiers, IGLC 2018 (pp. 144-154)

Morschheuser, B., Hamari, J., \& Koivisto, J. (2016). Gamification in crowdsourcing: a. In 2016 49th Hawaii International Conference on System Sciences (HICSS) (pp. 4375-4384). IEEE. Review

Moura Junior, R. (2020) Práticas colaborativas gamificadas para Prevenir Lesões por Pressão. Universidade Federal da Bahia (Tese do Doutorado Multidisciplinar e Multi-institucional em Difusão do Conhecimento (DMMDC).

Paul, R., \& Elder, L. (2003). Ethical reasoning. Dillon Beach, CA: The Foundation for Critical Thinking.

Pérez, C., \& Costa, D. (2019). Evaluation of 4D BIM use to reduce transportation waste in construction production processes. Simpósio Brasileiro de Gestão e Economia da Construção, 1-7. Londrina-PR

Pérez, C., Costa, D., \& Irizarry, J. (2020.) Algoritmos genéticos: uma abordagem visual para reduzir as perdas por transporte em canteiros de obra. Encontro Nacional de Tecnologia do Ambiente Construído, 18., 2020, Porto Alegre. Anais... ANTAC.

Petelczyc, C. A., Capezio, A., Wang, L., Restubog, S. L. D., \& Aquino, K. (2018). Play at work: An integrative review and agenda for future research. Journal of Management, 44(1), 161-190.

Ryan, R., \& Deci, E. (2017). Intrinsic and Extrinsic Motivations: Classic Definitions and New Directions, 2000. Contemporary Educational Psychology, 25, 54.

Sawhney, A., Riley, M., Irizarry, J., \& Pérez, C. (2020). A proposed framework for Construction 4.0 based on a review of literature. EPiC Series in Built Environment, 1, 301-309.

Schlemmer, E. (2018). Projetos de aprendizagem gamificados: uma metodologia inventiva para a educação na cultura híbrida e multimodal. MomentoDiálogos em Educação, 27(1), 42-69.

Seaborn, K., \& Fels, D. (2015). Gamification in theory and action: A survey. International Journal of human-computer studies, 74, $14-31$.

SEBRAE. (2019). Use a tecnologia para aumentar a produtividade na construção civil. https://www.sebrae.com.br/sites/PortalSebrae/artigos/use-a-tecnologiapara-aumentar-a-produtividade-na-construcao-civil,bc7e424bf57bf410VgnVCM1000004c00210aRCRD 
Research, Society and Development, v. 10, n. 12, e241101220293, 2021

(CC BY 4.0) | ISSN 2525-3409 | DOI: http://dx.doi.org/10.33448/rsd-v10i12.20293

Shahri, A., Hosseini, M., Phalp, K., Taylor, J., \& Ali, R. (2014). Towards a code of ethics for gamification at enterprise. In IFIP working conference on the practice of enterprise modeling (pp. 235-245). Springer, Berlin, Heidelberg.

Silva Junior, D., Santos, R., \& Santos, I. (2020). Industry Innovations 4.0 Process Management in the Provision of Services in the Construction Industry. Future Studies Research Journal: Trends and Strategies, 12(3), 394-415.

Silveira, B., Melo, R., \& Costa, D. (2020). Using UAS for Roofs Structure Inspections at Post-occupational Residential Buildings. In International Conference on Computing in Civil and Building Engineering (pp. 1055-1068). Springer, Cham.

Valente, C (2017). Modelo para concepção de dispositivos visuais na gestão da produção na construção (Dissertação de Mestrado) Universidade Federal do Rio Grande do Sul.

Vesa, M. (2021). Organizational Gamification: Roots, Readings, Directions. In Organizational Gamification (pp. 3-19). Routledge.

Vesa, M., den Hond, F, \& Harviainen, J. (2019). On the possibility of a paratelic initiation of organizational wrongdoing. Journal of Business Ethics, 160(1), $1-15$.

Vesa, M., Hamari, J., Harviainen, J., \& Warmelink, H. (2017). Computer games and organization studies. Organization Studies, 38(2), $273-284$.

Zichermann, G., \& Cunningham, C. (2011). Gamification by design: Implementing game mechanics in web and mobile apps." O'Reilly Média, Inc 